\title{
EXTRATO DO RELATÓRIO DO SECRETÁRIO DA FACULDADE DE DIREITO DA UNIVERSIDADE DE SÃO PAULO
}

1951 


\section{DIRETORIA}

Exercida, durante 1951, pelo Prof. Braz de Sousa Arruda.

\section{CONGREGAÇÃO}

Foram realizadas 8 sessões da Congregação durante o ano de 1951.

$1^{2}$. SESSÃO: 15-2-1951

o Prof. Soartes de Mello, propõe que as atas idas sessões da Congregação sejam mimeografadas e enviadas aos professores, a fim de que estes possam melhor tomar conhecimento de seu teor, antes da sessão em que devam ser lidas e submetidas a discussão.

Propõe, a seguir, o Prof. J. J. Cardozo de Mello Neto que os programas dos cursos sejam impressos separadamente, por cadeira, sem prejuizo da publicação do Anuário, que poderá reunir os impressos; as propostas dos Profs. Soares de Mello e Cardozo de Mello Neto foram aprovadas.

Passando-se à̀ ordem do dia, a Congregação verificou que se achavam prontos para o serviço do ano letivo os seguintes professores: Drs. Braz de Souza Arruda, J. J. Cardozo de Mello Neto, Vicente Ráo, Waldemar Ferreira, Mário Masagão, Gabriel de Rezende Filho, Ernesto Leme, Honório Monteiro, Lino Leme, Noé Azevedo, Soares de Mello, Cesarino Jr., Alvino Lima, Siqueira Ferreira, Miguel Reale e livres docentes Pinto Pereira e Gama e Silva. E mais os Profs. Soares de Faria, Ataliba Nogueira e Canuto Mendes de Almeida, que fizeram comunicação por escrito, nesse sentido.

o Sr. Diretor dá conhecimento à Congregação que os Profs. Ruy Cirne Lima, Alberico Fraga e Haroldo Valadão enviaram comunicação aceitando o convite para fazerem parte da comissão examinadora do concurso de Direito Constitucional.

A seguir, a Congregação procedeu à eleição para a vaga do Conselho técnico-Administrativo, na vaga do Prof. Ernesto Leme, 
tendo sido o nome do Prof. Honório Monteiro o mais votado, com doze votos, seguido pelo Prof. Waldemar Ferreira, com dez votos.

\section{2. ${ }^{\mathrm{a}}$ SESSÃO : 17-3-1951}

o Prof. Almeida Jr., apresenta as seguintes propostas, para que sejam submetidas à discussão e deliberação da Congregação: 1 - "Proponho que se represente ao Sr. Ministro da Educação, sobre a necessidade de serem simplificados os exames vestibulares, pelo menos nas escolas com grande número de candidatos. Conviria que esses exames se reduzissem às provas escritas." 2 "Proponho que, para o fim de seleção dos candidatos à transferência a esta Faculdade, sejam instituidas provas de classificação, sobre uma ou duas matérias do último ano frequentado pelo candidato". 3 - "Proponho que seja modificado o atual sistema de segunda chamada, pondo-se em vigor, na Faculdade, a exigência de atestado médico, nos termos do decreto-lei federal n.o 2.335 , de 24-6-1940" 4 - "Proponho que se estude e se organize, nesta $\mathrm{Fa}$ culdade, um sistema de verificação e registro de notas de alunos, que impeça as críticas, porventura injustas, algumas vezes feitas aos registros atuais".

Estas propostas foram postas em discussão, tendo resolvido a Congregação nomear comissão para estudá-las e dar parecer, comissão essa composta dos professores Waldemar Ferreira, Honório Monteiro e Soares de Faria.

Procedeu-se à eleição para renovação de membros do Conselho Técnico-Administrativo, cujo mandato terminará em Junho p. f., nuss termos do art. $18, \S 1^{\circ}$. Ida lei $n^{\circ}$. 3023 , alcançando na ordem de suas respectivas nomeações, os Profs. Noé Azevedo e Basileu Garcia. Obtiveram maioria de votos, em escrutínio secreto, os Profs. Waldemar Ferreira, com doze votos; Ataliba Nogueira, com doze votos; Basileu Garcia, com dez votos e Th. Monteiro de Barros Filho, com oito votos, os quais deverão ser indicados ao Magnífico Reitor, para efeito da renovação do Conselho Técnico-Administrativo desta Casa.

Pediu a palavra o Prof. Cesarino Jr., a fim de dar conhecimento aos colegas da ação que a Fazenda do Estado vinha contra ele movendo, para restituição de vencimentos supostamente pagos indevidamente. Fazia essa comunicação aos colegas, disse, na eventualidade de caso semelhante ocorrer com outro professor.

o Sr. Diretor, com a palavra, comunicou ter oferecido ao Prof. Cesarino Jr. os elementos necessários para contestar a referida ação, elementos que colocaria à disposição dos demais professores. 


\section{$-235-$ \\ 3. SESSÃO: 5-6-51}

Foi organizada, pela Congregação, lista de temas para a prova escrita do concurso para professor catedrático de Direito Constitucional, os quais deverão ser entregues aos candidatos a partir do dia 6 de Junho, realizando-se a prova escrita no dia 16, às 8 horas e as demais provas nos dias subsequentes, tambem pela manhā.

\section{SESSÃO 13-6-51}

Pelo sr. Diretor foi dito que convocara a presente reunião, em virtude de não dispor a Congregação dos dois terços de professores necessários para a votação do parecer em concurso e devendo ter início no dia 16 do corrente, as provvas para o mesmo, achava de bom aviso resolver a Congregação sobre a aplicação da lei 851, de 7-10-49, que permite que a Congregação que tiver menos de dois terços de professores catedráticos, indique, para completar esse número, professores catedráticos efetivos, de estabelecimentos cungêneres, oficiais ou reconhecidos, ou profissionais de notório saber, com atividades ou obras publicadas pertinentes à mesma disciplina.

Aberta a discussão, discorreram sobre o assunto os Profs. Cardozo de Mello Neto, Waldemar Ferreira, Th. Monteiro de Barros Filho, Siqueira Ferreira e outros.

o Prof. Waldemar Ferreira entende que se deve apelar aos professores ausentes para que reassumam os seus cargos, a fim de se completar o número de professores necessários.

o Prof. Th. Monteiro de Barros Filho propõe que se faça o apêlo, mas que se proceda, tambem, à indicação dos nomes das pessoas que deverão completar a Congregação.

Submetida a votos a próposta do Prof. Theotônio, foi a mesma aprovada, declarando o Prof. Siqueira Ferreira que entendia que deveriam ser convidados apenas desembargadores.

Procedeu-se, então, em votação secreta, à eleição dos nomes que deveriam completar a Congregação, com o seguinte resultado: desembargadores Antão de Moraes e Francisco Bernardes Jr., 11 votos; Dr. José Frederico Marques, 11 votos; Drs. Meirelles Teixeira e Paulo Bonilha: 8 votos; Ministro Manoel da Costa Manso: 6 votos; Manoel Carlos: 6 votos; Dr. Carvalho Pinto: 6 votos; Ministro Laudo de Camargo: 5 votos; desembargador Alcides Ferrari: 4 votos; Dr. Plínio Barreto: 4 votos; Dr. Alcides Vidigal: 4 votos; desembargador João Batista Leme da Silva: 4 votos; desembargador Silva Carneiro: 5 votos; desembargador Teodomiro Dias: 
2 votos; Prof. José Ulpiano Pinto de Souza: 2 votos; desembargador Azevedo Marques: 1 voto; Dr. Antonio de Queiroz Filho: 1 voto; Dr. Osvaldo Pinto: 1 voto e Dr. Abraão Ribeiro, 1 voto.

\section{$5^{\text {a }}$ SESSÃO : 22-6-51}

Sessão iniciada às 13 horas e 45 minutos, na sala João Mendes Jr., em prosseguimento dos trabalhos do concurso para professor catedrático de Direito Constitucional, sob a presidência do Prof. Braz de Sousa Arruda, Diretor, e com a presença dos seguintes professores catedráticos: Drs. Cardozo de Mello Neto, Sampaio Dória, Waldemar Ferreira, Gabriel de Rezende Filho, Ernesto Leme, Honório Monteiro, Soares de Faria, Soares de Mel1o, Alvino Lima, J. C. Mendes de Almeida, Ataliba Nogueira, Th. Monteiro de Barros Filho e livres docentes Drs. Pinto Pereira, Goffredo Telles Jr., Gama e Silva, Alexandre A. de Castro Corrêa e Hilário Veiga de Carvalho. Especialmente convidados, na forma do art. $1^{\circ}$. da lei 851 , de 7-10-49, achavam-se presentes os srs.: Ministro Costa Manso, Desembargadores Antão de Moraes e Francisco Bernardes Jr. e os drs. José Frederico Marques, Carlos A. A. de Carvalho Pinto e Paulo Bonilha. A Congregação esteve tambem presente nos dias 18, 19 e 20 de Junho, quando se realizaram as outras provas do concurso.

Aberta a sessão, achando-se tambem presentes os componentes da comissão examinadora, Profs. Albérico Fraga, da Faculdade de Direito da Universidade da Baía, Haroldo Valadão, da Faculdade Nacional de Direito da Universidade do Brasil, e Ruy Cirne Lima, da Faculdade de Direito de Porto Alegre, Rio Grande do Sul, eleitos pelo Conselho Técnico-Administrativo, e Profs. Ernesto Leme, e Th. Monteiro de Barros Filho, eleitos pela Ciongregação, teve lugar a prova didática dos candidatos inscritos.

Discorreram os três candidatos, Drs. José Pinto Antunes, Candido Motta Filho e Odilon Araujo Grellet, durante o prazo regulamentar de cinquenta minutos, marcado pela ampulheta e pelo cronômetro, sobre o ponto sorteado na 'véspera da lista organizada pela Comissão Examinadora, sob no. 32: Mandado de Segurança.

Findas as preleções, uma dada depois da outra, os srs. examinadores atribuiram notas aos candidatos, na forma da lei.

Procedeu-se à abertura da urna que continha as provas escritas dos candidatos, feitas no dia 16 de Junho, sobre o tema: "Revisão Constitucional. Direito de revolução", dda lista organizada pela Congregação.

Os candidatos procederam, em seguida, com fiscalização recíproca, à leitura das respectivas provas escritas. 
Os srs. examinadores atribuiram notas a cada uma das provas, em seguida à̀ sua leitura.

Foi, então, suspensa a sessão, para que a comissão examinadora procedesse à apuração das notas e elaborasse o seu parecer.

A Congregação, que se manteve em sessão permanente, enquanto a Comissão Examinadora ultimava seus trabalhos, passou a funcionar na sala habitual de suas sessões. Às 19,30 horas, deu entrada no recinto a comissão examinadora, procedendo o Prof. Ernesto Leme à leitura do seguinte parecer:

\section{PARECER DA COMISSÃO DO CONCURSO PARA PROFESSOR CATEDRÁTICO DE DIREITO CONSTITUCIONAL}

A Comissão Exminadora do concurso para professor catedrático de Direito Constitucional, de que participaram os drs. José Pinto Antunes, Candido Motta Filho e Odilon Araujo Grellet, vera apresentar à Egrégia Congregação o seu parecer.

o concurso teve início no dia 16 de junho de 1951, com o julgamento dos títulos e a prova escrita de todos os icandidatos, realizando-se as demais provas nos dias 18, 19, 20 e 22 do mesmo mês.

Terminadas as provias, a Comissão Examinadora, reunida na Sala João Mendes Jr., desta Faculdade, em público, procedeu à apuração das notas atribuidas aos candidatos nas diversas provas, verificañdo-se o seguinte resultado:

Os examinadores professores Albérico Fraga, Th. Monteiro de Barros Filho e Ernesto Leme classificaram em 10. lugar o Dr. Candido Motta Filho, com as médias, respectivamente, 9, 25, 9, 25 e 9.

O Dr. José Pinto Antunes teve as seguintes médias: Prof. Albérico Fraga, 3,5; Prof. Haroldo Valadão, 7,75; Prof. Ruy Cirne Lima, 8,5, Prof. Th. Monteiro de Barros, 8,25; Prof. Ernesto Leme, 8,25 .

O Dr. Odilon Araujo Grellet obteve as seguintes médias: dos Profs. Albérico Fraga, Haroldo Valadão, Ruy Cirne Lima, 7; dos Profs. Monteiro de Barros Filho e Ernesto Leme, 6,5.

À vista do resultado exposto, a comissão examinadora, por três votos contra dois, indica para a cátedra de Direito Constitucional o livre docente Dr. Candido Motta Filho, fazendo parte integrante deste parecer o quadro geral das notas atribuídas aos candidatos nas diversas provas, quadro esse por ela assinado. São Paulo, 22 de Junho de 1951. as) Ernesto Leme, Ruy Cirne Lima, Albérico Fraga, Haroldo Teixeira Valadão, Th. Monteiro de Barros Filho. 
o Prof. Braz de Sousa Arruda apresentou os agradecimentos da Faculdade aos eminentes juristas que compuzeram a Comissão Examinadora e aos que completaram o número da Congregaçâo.

Responderam agradecendo os srs. Prof. Ruy Cirne Lima e Dr. Paulo Bonilha.

O Sr. Diretor enalțeceu a importância da cátedra de Direito Constitucional, salientando a figura de Herculano de Freitas, como professor dessa disciplina.

\section{$6^{\mathrm{a}} \cdot \operatorname{SESSÃO}-2-10-51$}

Sesssäo Especial

A Congregação tomou conhecimento das inscrições no concurso à livre docência no corrente ano, tendo concorrido os bachareis: José Cretella Jr., em Direito Administrativo; e Silvio Rodrigues, em Direito Civil. Foram aprovadas, unanimemente, ambas as inscrições.

Logo após, o Prof. Gabriel de Rezende Filho propoz que os concursos se realizem em Março de 1952, no inicio das aulas.

Essa proposta, submetida a votos, obteve empate; o sr. Diretor, usando da atribuição que lhe concede $o$ art. 30 da lei no. 2023, desempatou a favor ida proposta Gabriel de Rezende Filho.

Foram, a seguir, eleitas as seguintes comissões examinadoras:

Direito Administrativo: Profs. Cardozo de Mello Neto, Mário Masagão, Ataliba Nogueira, Th. Monteiro de Barros Filho e Candido Motta Filho.

Suplentes: Profs. Gabriel de Rezende Filho e Cesarino Junior.

Direito Civil: Profs. Vicente Ráo, Jorge Americano, Lino Leme, Alvino Lima e Honório Monteiro.

SUPLENTES: Profs. Waldemar Ferreira e Soares de Faria.

$$
\text { 7 } \text {. SESSÃO - 13-12-51 }
$$

o Sr. Diretor comunicou à C'ongregação as deliberações do Conselho Universitário relativas à desapropriação dos prédios da Rua Riachuelo e ddas heranças jacentes, tendo lido as cópias das respectivas deliberações.

A Congregação ficou ciente do ofício SG/568, de 19-11-51, da Reitoria da Universidade, sobre a situação do Prof. Almeida Jr., no Conselho Nacional de Educação. À vista da resposta do Presidente daquele Conselbo, constante do referido ofício, a Congregação entendeu que mada havia a deliberar sobre o assunto. 
Continuando a leitura do expediente, ciente do projeto de lei $\mathrm{n}^{\circ} .1 .300 \mathrm{da}$ Assembleia Legislativa de São Paulo, relativo à criação de seminários junto às cátedras desta Faculdade, a Congregação resolveu que uma comissão, designada pelo Sr. Diretor, ficasse encarregada de estudar o referido projeto, e qualquer outro assunto que interessassse à Faculdade, porventura existente na Assembleia.

o Sr. Diretor designou os professores Cardozo de Mello Neto, Waldemar Ferreira e Soares de Faria, para comporem a referida comissão.

o Prof. Mário Masagão pediu a sua substituição na comissão examinadora do concurso à livre docência de Direito Administrativo, por ter de examinar, na mesma ocasião, na Faculdade de Direito de Minas Gerais.

Por proposta do Prof. Basileu Garcia, aprovada pela Congregação, ficou estabelecido que o concurso desta Faculdade seria adiado por quinze dias, a fim de contar com a colaboração do Prof. Mário Masagão.

Finalmente, foi lido o ofício do Presidente do Centro Acadêmico XI de Agosto, solicitando, em nome dos bacharelandos de 1951,

1 ${ }^{\circ}$. - que a solenidade de colação de gráu fosse realizada no Teatro Municipal, devido ao grande número de bacharelandos;

$2^{\circ}$. - que da mesma participassem todos os bacharelandos, mesmo os dependentes de $2^{a}$. época;

$3^{\circ}$. - que se realizasse a colação no dia 11 de Janeiro.

A Congregação indeferiu o solicitado nos $1^{\circ}$. e $2^{\circ}$. itens, concedendo apenas a data pedida.

Foi, ainda, discutido e votado o projeto sobre os auxiliares de ensino, artigo por artigo, sendo aprovada a emenda do Prof. Cardozo de Mello Neto, sobre o art. 10., que ficou assim redigido:

Art. $1^{\circ}$. - Será contratado um auxiliar de ensino para cada uma das cadeiras do curso de bacharelado, quando o julgar conveniente o respectivo catedrático.

A Congregação resolveu adiar, devido ao adiantado da hora, a discussão do assunto para a próxima sessão.

$$
\text { 8. SESSÃO - 20-12-1951 }
$$

o Sr. Diretor fez um apelo à Congregação, a fim de ser resolvida a situação dos alunos do Curso de Doutorado 
Em seguida, foi lido um oficio do Prof. Joaquim Canuto Mendes de Almeida, que representou a Faculdade de Direito no I Congresso Hispano-Luso-Americano de Direito Internacional, realizado em Madrí, em Outubro d,êste ano, no qual se deliberou que o Congresso se reunisse pela segunda vez em São Paulo, em Outulbro de 1953, em homenagem aos brasileiros e em comemoração ao IV Centenário da fundação de São Paulo.

Em seguida, o Sr. Diretor fez diversas considerações sobre o intercâmbio de professores, salientando a viagem do Prof. J. C. Mendes de Almeidā e do Prof. Pinto Pereira.

Falou, ainda, o Sr. Diretor, sobre o contrato de professores estrangeiros, entre os quais enumerou os Profs. Barcia Trelles e Bagolini, que deverão ser contratados no próximo ano.

Ainda durante o expediente, pelo Prof. Cesarino Jr. foi dito que comparecera ao Congresso do Trabalho, realizado em Trieste, representando a Univversidade de São Paulo, tendo sido um dos presidentes eleitos do referido Congresso. Aguardou que a Reitoria fizesse comunicação à Faculdade ıdo relatório que apresentara, como era seu dever, ao Magnúfico Reitor, sendo esta a razão de sómente nesta data trazer o fato ao conhecimento dos colegas.

Passando-se à ordem do dia, a Congregação discutiu e passou a votar os diversos artigos do regulamento relativos aos auxiliares ide ensino.

O Prof. Waldemar Ferreira apresentou idiversas emendas substitutivas do ante-projeto elaborado pelo C. T. A., de modo que a Congregação resolveu dar preferência à discussão e votação dessas emendars.

Discutidas e votadas as emendas, o regulamento dos auxiliares de ensino ficou com a seguinte redação final:

Art. 10. - Serão contratado um auxiliar de ensino para cada uma das cadeiras do curso de bacharelado, quando o julgar conveniente o respectivo professor.

Art. 2०. - Compete ao auxiliar de ensino:

a) acompanhar os cursos do catedrático, de molde a poder repetir aos alunos a matéria explicada e realizar os trabalhos práticos por ela ensejados;

b) acompanhar e orientar as pesquizas e trabalhos escritos dos alunos, determinados pelo catedrático;

c) seguir o movimento bibliográfico da matéria da cadeira, quer de livros, quer de artigos de revistas, recebidos pela $\mathrm{Bi}$ blioteca, fazendo súmulas que, trimestralmente, serão mi- 
meografadas e distribuidas aos alunos e professores e e publicadas na Revista;

d) promover e realizar visitas a institutos e estabelecimentos científicos e profissionais, condizentes com a matéria explicada pelo catedrático, ministrando aos alunos explicações de sua finalidade e condições de seu funcionamento;

e) realizar trabalhos científicos ou práticos referentes à cadeira, que the forem atribuidos pelo professor;

f) apresentar anualmente ao catedrático relatório circunstanciado dos trabalhos realizados e do gráu de aproveitamento dos alunos, fazendo sugestões para a maior eficiência de suas funções.

Art. 3.० - E vedado ao auxiliar de ensino, que não seja livre docente, substituir o professor na explicação do programa.

Art. 4..$^{-} 0$ catedrático poderá escolher livremente, dentre os livres docentes, o seu auxiliar de ensino.

Art. 5. - Caso não seja livre docente, o candidato ideve ser bacharel em direito, ou médico, tratando-se da cátedra de Medicina Legal, formado há mais de dois anos, cumprindo-lhe apresentar trabalhos, publicados ou não, especializados na matéria.

$\S 10^{\circ}$ - Nesta hipótese, proceder-se-á a exame de habilitação, perante banca formada pelo professor proponente e mais dois catedráticos escolhidos pelo C.T.A.;

$\S 20^{\circ}$ - Constará o exame de prova escrita e de prova prática oral sobre ponto do programa, sorteado com vinte e quatro horas de antecedência para cada prova.

$\S 3 .^{\circ}$ - Findas as provas, os examinadores, por maioria, habilitarão ou não o candidato;

$\S 40^{\circ}$ - Nenhum professor fará parte da banca examinadora quando o candidato for seu consanguineo até ao terceiro gráu.

Art. 6.0 - 0 candidato habilitado será contratado por dois anos, podendo o contrato ser renovado.

$\S$ único - $\mathrm{O}$ auxiliar de ensino, antes de completar quatro anos de exercicio, ficará obrigado a inscrever-se em concurso para livre docente, sołb pena de não ser renovado o contrato, ficando êste rescindido no caso de inhabilitação ou de não comparecimento ido candidato às provas.

Art. 7.0 - 0 contrato de auxiliar de ensino pode ser rescindido a qualquer tempo, por solicitação do professor.

Art. $80^{\circ}-\mathrm{O}$ auxiliar de ensino perceberá os vencimentos fixados em lei.

Art. 9.0 - Começará a vigorar o presente regulamento no inicio do curso juridico de 1952. 


\section{CONSELHO TÉCNICO-ADMINISTRATIVO}

\section{1. ${ }^{a}$ SESSÃO 16-1^1951}

Foram organizados os pontos para as provas escritas de Filosofia e História da Civilização, nos próximos exames vestibulares.

Em seguida, o Conselho elegeu as seguintes comissões examinadoras dos exames vestibulares: Latim: Profs. Lino Leme e Soares de Faria e livre docente Dr. Alexandre Augusto C. Corrêa: Português: Profs. Sampaio Dória e livres docentes Drs. Gama e Silva e Alfredo Buzaid; Francês: Profs. Th. Monteiro de Barros Filho e Almeida Jr. e livre docente Dr. Paulo Barbosa de Campos Filho; Inglês: Prof. Jorge Americano e livres docentes Drs. Pinto Pereira e Ester de Figueiredo Ferraz.

O Sr. Diretor foi autorizado a fazer as substituições por ventura necessárias, nas comissões acima.

Logo após, o Conselho designou o Prof. Noé Azevedo para reger a cadeira de Criminologia, do curso de doutorado, no corrente ano.

\section{2." SESSÃO 13-2-1951}

O Conselho autorizou o Sr. Diretor a admitir os pedidos de transferência para o curso de bacharelado, na ordem de precedência dos requerimentos apresentados e de acôrdo com as vagas existentes nos cursos diurno e noturno.

O Sr. Diretor, outrossim, foi autorizado a pedir o contrato do Prof. Luigi Bagolini, da Universidade de Bologna, para organizar o seminário de Filosofia do Direito, nos meses de maio a novembro do corrente ano.

\section{3. ${ }^{\mathrm{a}}$ SESSÃO 5-4-1951}

Foram deferidos os requerimentos de pedidos de recondução à livre docência dos Drs. Goffredo da Silva Telles Jr. e Silvio Marcondes Machado, respectivamente das cadeiras de Introdução à Ciência do Direito Comercial.

Foi confiado ao Prof. Honório Monteiro o estudo da questão de ser eliminatória ou não a cadeira de Introdução à Ciência do Direito, à vista do requerimento do Presidente do Centro Acadêmico XI de Agosto. 


\section{4." SESSÃO 8-5-1951}

O Conselho resolveu:

- autorizar a matrícula no curso noturno de alunos que a: requereram em tempo hábil e que aguardavam deferimento, por falta de vaga;

- baixar uma Portaria, assinada pelo Sr. Diretor, prevenindo. os alunos do $10^{\circ}$ ano sôbre a eliminatoriedade da cadeira de Introdução à Ciência do Direito;

- em face da comunicação feita pelo Sr. Diretor, da existência no orçamento da Faculdade, de verba própria para concessão de prêmios aos alunos desta Casa, instituir cinco prêmios. de dez mil cruzeiros cada um, a serem conferidos aos alunos que, em cada um dos anos do curso de bacharelado obtiver, respectivamente, em primeira época, a maior média geral do ano que estiver cursando, sendo que na hipótese de existir mais de um aluno em cada ano, com média igual, o prêmio será conferido àquele que os professores indicarem, por maioria de votos, ao julgar trabalho escrito, apresentado sobre assunto previamente indicado pelos mesmos professores.

\section{6..$^{2}$ SESSÃO 12-6-1951}

0 Conselho resolveu:

deferir o requerimento de recondução na livre docência de Direito Civil do Dr. Octávio Moreira Guimarães;

- deferir o pedido de prorrogação de contrato do Prof. Caetano Sciascia, desde que esteja de acôrdo o professor da cadeira de Direito Romano, Dr. Alexandre Correia;

- deferir, estando de acôrdo os professores Gabriel de Rezende Filho e Soares de Faria, o pedido dos livres docentes Drs. Alfredo Buzaid e Luiz Eulálio de Bueno Vidigal, para a realização de um curso de especialização na cadeira de Direito Judiciárió Civil, para os alunos dos $4 .^{\circ}$ e $5 .^{\circ}$ anos.

\section{9.* SESSÃO 30-11-1951}

O Conselho resolveu:

- aprovar o projeto sobre auxiliares de ensino, apresentado pelo Prof. Ataliba Nogueira, remetenło-o à Congregação;

- quanto à reforma do Curso de Doutorado, aceitar o projeto do Prof. Th. Monteiro de Barros Filho, com a seriação constante do projeto Ataliba Nogueira, incluindo-se Direito Internacio- 
nal Público, de modo que se possam estudar os órgãos de política internacional, como a O.N.U. e outros (proposta do Prof. Honório Monteiro), a título de sugestões a serem apresentadas à Congregação. Esta deliberação foi tomada devido ao estudo das diversas propostas apresentadas, ficando o Prof. Ataliba Nogueira encarregado da redação final do projeto;

\section{PORTARIAS DO SR. DIRETOR}

Portaria 1/15 - 10-1-1951 - Exonerando, a pedido, o Sr. Antonio Caetano, das funçōes de servente diarista.

Portaria 2/15 - 10-1-1951 - Concedendo licença para tratamento de saúde ao Proflessor Sampaio Dória, dessa data até 23 de Janeiro.

YY

Portaria 3/15 - 17-1-195.1 — Designando o Sr. Alvaro Augusto Lopes para exercer as funçōes de servente diarista.

Portaria 4/15 - 3-3-1951 — Designando o Sr. Joaquim de Oliveira para fiscalizar a limpesa da Faculdade, como auxiliar do Sr. Porteiro.

Portaria 5/15 -3-4-195- - Reconduzindo por mais 10 anos 10 Dr: Goffredo da Silva Telles Jr. no cargo de livre docente de Introdução à Ciência do Direito.

Portaria 6/15 - 3-4-1951 - Reconduzindo por mais 10 anos o Dr. Silvio Marcondes Machado no cargo de livre docente de Direito Comercial.

Portaria 7/15 - 2-5-1951 - Concedendo licença para tratamento de saúde ao Professior Jorge' Americano, por quarenta e cinco dias.

Portaria 8/15 - 18-5-1951 - Sem efeito.

Portaria 9/15 - 29-5-1951 - Exonerando, a pedido, o Sr. Carlos Rockmann, das funções de servente diarista.

Portaria.10/15 - 2-7-1951 - Designando o Sr. Benedicto Pereira para exercer as funçōes de servente diarista.

Portaria 11/15 - 2-7-1951 - Designando o Sr. Otacilio Nunes de Oliveira para exercer as funções de siervente diarista.

Portaria 12/15 - 9-8-1951 — Reconduzindo por mais 10 anos o Dr. Octávio Moreira Guimarães no cango de livre docente de Direito Civil.

Portaria 13/15 — 17-8-1951 - Nomeando o Dr. Odilon Araujo Grellet para lugar de livre docente da cadeira de' Direito Constitucional. 
Portaria 14/15 - 1. $0^{\circ}-9-1951$ - Exonerando, a pedido, o Sr. Rubeñs Galo de Arruda, das funções de servente diarista.

Portaria 15/15 - Designando D. Jasmina Mendonça para exercer as funções de servlente diarista. 12-9-1951.

Portaria 16/15 - 24-9-1951 - Designando a Dra. Esther de Figueinedo Ferraz para reger a turma desdobrada de Direito Penal, 4..$^{\circ}$ ano.

Portaria 17/15 — 24-9-195- - Desígnando o Dr. Vicente de Paulo Vicente de Azevedo para reger a turma desdobrada de Direito Judiciário Penal do $5 .^{\circ}$ ano, curso diurno e noturno.

Portaria do Sr. Diretor de 2 de Janeiro - Concedendo licença para Portaria 17/15 — 24-9-1951 — Designando o Dr. Vicentie de Paulo Direito Judiciário Penal do $5 .^{\circ}$ ano, cursos diurno e noturno.

Professor Sampáio Dória — Foi-lhe concedida licença para tratamento de saude, de 2 a 23 de janeiro. Por decreto do Senhor Presidente da República, de 19 de janeiro, foi aposentado de

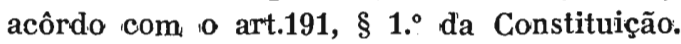

Docente Livre Luiz Antônio da Gama e Silva - Substituiu o Prof. Sampáio Doria na regência da cadeira de Diretor Internacional Privado do $50^{\circ}$ ano. Nomeado, por decreto do Governador do Estado de 22 de fevereiro, para exercer interimamente o cargo de Professor Catedrático, na vaga decorrente com a aposentadoria do Prof. Sampaio Doria.

Professor Honório Monteiro - Nomeado para exercer a função de membro do Conselho Técnico Administrativo, por ato do Magnifico Reitor de 5 de Março.

Professor Miguel Reale - Afastado da regência da cadeira de Introdução à Ciêncỉa do Direito. do $10^{\circ}$ ano, para a qual fôra designado em substituição ao Prof. Spencer Vampré. Colocado a disposição do Ministério do Trabalho, Indústria e Comércio, a portir de $10^{\circ}$ de junho, pelo prazo de sessenta dias, a fim de integrar a Delegação do Govêrno Brasileiro á 34A Sessão da Conferência Internacional do Trabalho realizada em Genebra no mês de junho de 1951 .

Docente Livre Goffredo da Silva Telles Junior - Nomeado para substiturir o Prof. Spencer Vampré na regência da cadeira de Introdução á Ciência do Direito do $10^{\circ}$ ano.

Professor Alexandre Correia - A partir de 7 de abril, em gôzo de um mês de ličença-prêmio. A partir de 22 de maio, em gôzo de um mês de licença-prêmio, em prorrogação. A partir de 15 de junho, em gôzo de um mês de licença-prêmio em prorrogação. A partir de 10 de agôsto, três meses de licença prêmio em prorrogação. 
Professor Luigi Bagoline - Contratado para organizar um Seminário de Filosofia nesta Faculdade, no periodo de maio a novembro mediante o salário de professor catedrático, aprovado pelo Colendo Conselho Universitário.

Professor Basileu Garcia - Dois meses em gôzo de licença prêmio. Nomeado para exercer funções de membro do Conselho Técnico Administrativo desta Faculdade. Substituiu o Prof. Noé Azevedo na regência da cadeira de Criminologia, do $10^{\circ}$ ano do Curso de Doutorado.

Professor Jorge Americano - Concedidos quarenta e cinco dias para tratamento de saude.

Professor Cardoso de Mello Neto - Designado para substituir o Prof. Theotonio de Barros Filho, na regência da cadeira de Ciência das Finanças, do $20^{\circ}$ ano.

Professor Ernesto de Moraes Leme — Afastado pelo prazo de vinte dias, em carácter excepcional, para participar das solenidades do IV Centenário da Universidade Nacional Mayor de São Marcos, em Lima, Perú.

Docente Livre Silvio Marcondes Machado - Nomeado para substituir o Prof. Erneisto de Moraes Leme na regência da cadeira de Direito Comercial do $40^{\circ}$ ano, por decreto de 10 de maio. Nonomeado por decreto de 14 de agôsto para substituir o Prof. Ernesto de Moraes Leme, na regência da cadeira de Dirreito Comercial, durante o impedimento dêsse Professor como Reitor da Universidade de São Paulo. Nomeado para substituir o Prof. Waldemar Ferreira na regência da cadeira de Direito Comercial, do $3 .^{\circ}$ ano do Curso de Bacharelado, durante o afastamento dessie professor.

Docente Livre Percival de Oliveira - Nomeado para substituir o Prof. Basileu Garcia na regência da cadeira de Direito Penal do $3 .^{\circ}$ ano, durante $o$ impedimento desse professor.

Professor Cesarino Junior - Afastado no periodo de 5 de maio a 5 de junho, a fim de participar do I Congresso Ibero-Americano de Segurança Social e do I Congresso Internacional de Direito do Trabalho a realizar-se em Trieste.

Docente Livre Octávio Moreira Guimarães - Nomeado para substituir o Prof. Jorge Americano, na regência da cadeira de Direito Civil do 2..$^{\circ}$ ano, durante o afastamento dêsse professor para tratamento de saude. Nomeado para substituir o Prof. Lino Leme na regência da cadeira de Direito Civil do $10^{\circ}$ ano do curso de bacharelado, durante o impedimento dêsse professor por motivo de licença-prêmio. 
Docente Livre Alexandre Augusto de Castro Corrêa - Nomeado para substituir o Prof. Alexandre Correia na regência da cadeira de Direito Romano, do $10^{\circ}$ ano, em virtude da licença-prêmio concedida a êsse professor.

Professor José Carlos de Ataliba Nogueira - Foi-lhe concedida mais a sexta parte de seus vencimentos a partir de 16 de novembro de 1950. Nomeado para exercer as funções de membro do Conselho Técnico Administrativo desta Faculdade.

Professor Antônio Ferreira de Almeida Junior - Foram-lhe concedidas seis meses de licença prêmio, por decreto de 28 de máio e de 22 de argosto.

Professor Joaquim Canuto Mendes de Almeida - Tornado sem efeito io ato publicado a 17 de maio, que o colocara à disposição do Ministério do Trabalho, Indústria e Comércio, pelo prazo de sessenta dias a fim de integrar a Delegação do Govêrno Brasilleiro à $34 .^{*}$ sessão da Conferência Internacional do Trabalho, a neunir-se em Genebra. Foram-lhe concedidos sessenta dias de afastamento a fim de representar a Faculdade de Direito no "Primier Congnese Hispano-Luso-Americano de Derecho Internacional" em Madrí.

Docente Livre Hilário Veiga de Carvalho - Designado para substituir o Prof. Almeida Junior, na regência de Medicina Legal, do 4. ${ }^{\circ}$ ano do curso de bacharelado, durante o impedimento desse professor por motivo de licença-prêmilo.

Professor Contratado Caetano Sciascia - Foi prorrogado por dois anos, seu contrato para continuar a exercer funções de Auxiliar de Ensino junto à cadeira de Dineito Romano do $1 .^{\circ}$ ano do curso de Bacharelado.

Professor Lino de Ns,oraes Leme - Foram-lhe concedidos três meses de licença-prêmio.

Professor Candido Motta Filho - Nomeado para exercer o cargo de professor catedrático de Dineito Constitucional. Designado para substituir o Prof. Mário Masagão na regência da cadeira de Direito Administrativo, do $5 .^{\circ}$ ano do Curso de Bacharelado, durante $o$ impedimento dêsse professor por motivo de licença prêmio. Foram-lhe' concedidos três meses de afastamento, a fim de empreender viagem de estudos à Portugal, Espanha e França.

Docente Livre Manoel Francisco Pinto Peneira - Designado para substituir o Prof. Braz de Sousa Arruda, durante o impedimento dêsse professor como Diretor desta Faculdade. Foram-lhe concedidos três meses de afastamento, por ato de 26 de setembro, a fim de acompanhar os cursos da Academia de Direito Internacional de Haia. 
Professor Alvino Ferreira Lima - Designado para substituir o Prof. Lino Leme' na regência da cadeira de Direito Civil Comparado, do $1 .^{\circ}$ ano do curso de Doutorado, durante o impedimento dêsse professor por motivo de licença-prêmio. Foram-lhe concedidos três meses de afastamento, a fim de empreender viagem de estudos a França, Bélgica e Holanda.

Docente Livre Luiz Eulálio de Bueno Vidigal - Designado para ministrar um curso de aperfeiçoamento de Direito Judiciário Civil aos alunos dos $4 .^{\circ}$ e $50^{\circ}$ anos.

Docente Livre Alfredo Buzaid - Designado para ministrar um curso de aperfeiçoamento de Direito Judiciário Civil aos alunos dos $4 .^{\circ}$ e $5 .^{\circ}$ anos.

Professor Gabriel de Rezende Filho - Foi-lhe concedida, a partir de 10 de julho de 1947, mais a sexta parte de seus vencimentos. Foi-lhe concedido ưm mês de licença-prêmio.

Professor Waldemar Ferreira - Fioram-lhe concedidos sessenta dias de afastamento, a fim de representar a Universidade de São Paulo nas festas comemorativas do IV Centenário da Universidade de São Paulo nas festas ioomemorativas do IV Centenário da Universidadie Nacional Autônoma de Chicago, Estados Unidos da América do Norte.

Professor Mário Masagão - Foi-lhe concedido um mês de licença prêmio.

Professor Noé Azevedo - Foram-lhe concedidos três meses de licença prêmio. Foi designado para reger a cadeira de Criminologia do 1. ano do Cunso de Doutorado.

Professor B. de Siqueira Ferreira - Designado para substituir o Prof. Waldemar Ferreira, na regência da cadeira de História do Direito Nacional, do $10^{\circ}$ ano do Curso de Doutorado, durante o impedimento dêsse professor.

Professor Spencer Vampré — Foram-lhe concedidos em prorrogação, trezentos e sesisenta e cinco dias de afastamento.

Docente Livre Vicente de Paulo Vicente de Azevedo - Foi ratificada a Pontaria n. $17 / 15$ do Sr. Diretor da Faculdade, de 24-9-51, que o Idesignara para neger as turmas desdiobradas dos cursos diurno e noturno da cadeira de Dirreito Judiciário Penal do $5 .^{\circ}$ ano do Curso de Bachanelado, em substituição ao Prof. Joaquim Canuto Mendes de Almeida.

Docente Livre Esther de Figueiredo Ferraz - Ratificada a Portaria n. 16/15, do Sr. Direitor da Faculdade, de 24-9-51, que a designara para reger a turma desdobrada da cadeira de Direito Penal do 4. ano, em substituição ao Prof. Noé Azevedo. 
Docente Livre João de Deus Cardozo de Mello - Nomeado para substituir o Prof. Joaquim Canuto Mendes de Almeida na regência da cadeira de Direito Judiciário Penal, do $50^{\circ}$ ano do Curso de Bacharelado.

Docente Livne Flávio Queiroz de Moraes - Nomeado para substituir o Prof. Noé Azevedo na regência da cadeira de Direito Penal, do $4 .^{\circ}$ ano do curso de Bacharelado.

Docente Livre José Dalmo Fairbanks Belfor de Mattos — Substituiu o Prof. Braz de Sousa Arruda, na regência da cadeira de Direito Internacional Público, do $4 .^{\circ}$ ano, durante o afastamento do Prof. Pinto Ferreira.

Docente Livre Genésio de Almeida Moura — Substituiu o Prof. Cândido Motta Filho, na regência da cadeira de Direito Constitucional do 2. ${ }^{\circ}$ ano do Curso de Bacharelado.

13 de Abril - Aula solene de abertura dos cursos jurídicos, no corrente ano letivo, tendo sido a respectiva preleção proferida plelo Prof. Alexandre Correia.

11 de Agosto - Aniversário do $124 .^{\circ}$ aniversário da fundação dos cursos juridicos no Brasil, constando as solenidades de:

às 9 horas — Missa na Igreja de São Francisco;

às 10 horas - Sessão solene da Congregação, realizada no Salão Nobre, tendo falado o Prof. Ataliba Nogueira, em nome da Congregação e um representante do Centro Acadêmico XI de Agosto.

11 de Setembro - Visita da Embaixada dos Estudantes da Universidade de Coimbra, constando as solenidadies de:

às 9 horas - Aula do Prof. Dr. Eduardo Correia, da Universidade de Coimibra, sobre "Rumos da Criminologia e Direito Criminal",

às 10 horas - Visita à Faculdade e ao Centro Acadêmico XI de Agosto;

às 21 horas - Sessão solene no Salão Nobre da Faculdade, para a cerimônia da entrega do título de "doutor honoris causa" ao Prof. Maximinio Correia, Magnifico Reitor da Universidade de Coimbra. que pronunciou uma conferência. Falou em nome da Congregação o Prof. Sioares de Mello.

12 de Outubro — Sessão comemorativa do $5 .^{\circ}$ centienário do nascimento da Rainha Isabel, a Católica, realizada às 10 horas, na 
Sala João Mendes, falando, em nome da Congregação, o Prof. Ataliba Nogueira.

14 de Novembro - Aula solene de encerramento dos cursos juridicos, no ano letivo de 1951, proferida pelo Prof. Candido Motta Filho, realizada no Salão Nobre da Faculdade.

Em 11 de Janeiro de 1952: - Cerimônia da colocação de gráu dos bacharelandos de 1951, com io seguinte programa:

às 9 horas - Missa na Igreja de São Francisco.

às 21 horas - Sessão solene no Salão Nobre da Faculdade, tendo colado gráu duzentos e trinta e três bacharelandos. Foi paraninfo 'o Prof. Migue] Reale.

\section{ALUNOS MATRICULADOS EM 1951 NO CURSO DE BACHARELADO}

1. Ano:

Sexo masculino

Dependentes

151 Sexo feminino 292

443
CURSO DIURNO

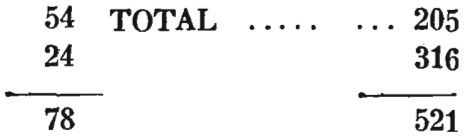

\section{CURSO DIURNO}

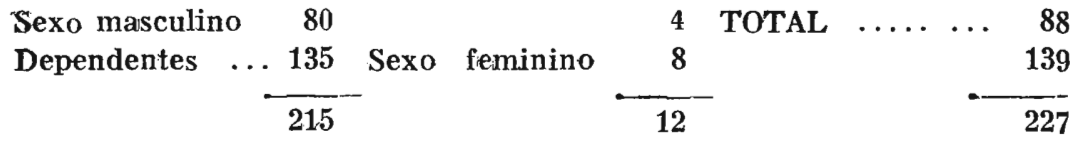

TOTAL DE ALUNOS DOS DOIS PERIODOS:

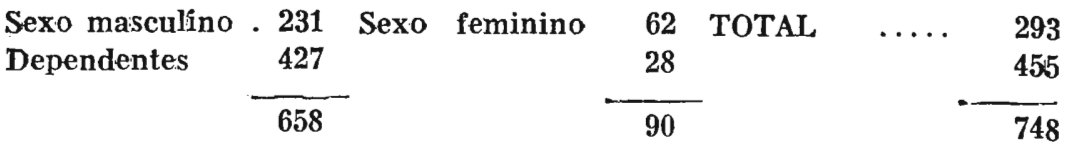

2. Ano:

Sexo masculino 336 Sexo feminino Dependentes ... 169

CURSO DIURNO
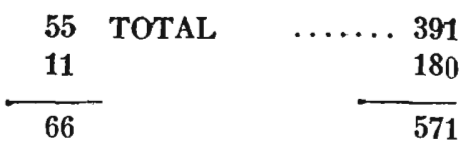
CURSO NOTURNO

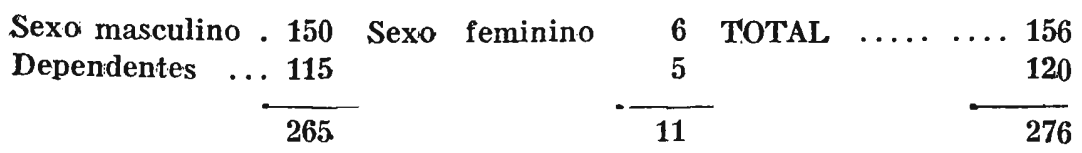

TOTAL DE ALUNOS DOS DOIS PERfODOS:

Sexo masculino . 486 Sexo feminino 61 TOTAL ....... 547

Dependentes ...284 $16 \quad 16 \quad 300$

$\overline{770}^{-} \quad 7^{-}-\overline{847}$

3. Ano:

CURSO DIURNO

Sexo masculino 223 Sexo feminino 26 TOTAL .....249

$\begin{array}{lllll}\text { Dependentes } & \ldots & 106 & 7 & 113\end{array}$

$3 2 9 \longdiv { 3 3 } \quad \overline { 3 6 2 }$

CURSO NOTURNO

$\begin{array}{lllllllll}\text { Sexo masculino } & 140 & \text { Sexo feminino } & \ldots & 6 & \text { TOTAL } & \ldots & \ldots & 146\end{array}$

$\begin{array}{lllll}\text { Dependentes } & \ldots & 51 & 1 & 52\end{array}$

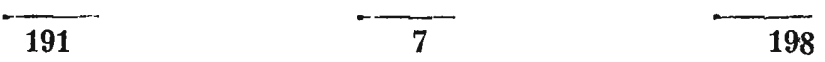

TOTAL DE ALUNOS DOS DOIS CURSOS:

Sexo masculino . 363 Sexo feminino 32 TOTAL $\ldots \ldots \ldots 395$

$\begin{array}{lllll}\text { Dependentes } & \ldots & 157 & 8 & 165\end{array}$

$\overline{520}+\frac{}{40} \quad \cdots 5$

4. Ano:

CURSO DIURNO

Sexo masculino . 329 Sexo feminino .. 39 TOTAL $\ldots . . . .331$

$\begin{array}{lllll}\text { Deplendentes } & \ldots & 84 & 5 & 89\end{array}$

$-\overline{376} \quad \frac{5}{44}$

CURSO NOTURNO

Sexo masculino 113 Sexo feminino 2 TOTAL ........ 115

Dependentes $\ldots 33 \quad 33003$

$1 4 6 \longdiv { 2 }$ 
TOTAL DE ALUNOS DOS DOIS PERfODOS:

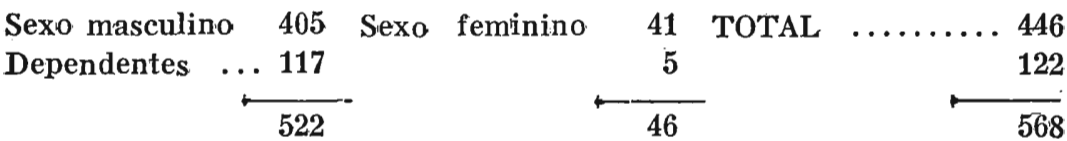

5. Ano:

CURSO DIURNO

Sexo masculino . 221 Sexo feminino -26 TOTAL $\ldots \ldots \ldots 247$

CURSO NOTURNO

$\begin{array}{llllllllll}\text { Sexo masculino } & 83 & \text { Sexo feminino } & . . & 0 & \text { TOTAL } & \ldots . & \ldots & 83\end{array}$

TOTAL DE ALUNOS DOS DOIS PERfODOS:

Sexo masculino . 304 Sexo feminina .. 26 TOTAL $\ldots \ldots . .330$

\section{TOTAIS GERAIS}

A - 1. ${ }^{\circ}$ ANO: 748 alunos

2. ${ }^{\circ}$ ANO: 847

3. ANO: 560 "

4. ${ }^{\circ}$ ANO: 560 "

5. ANO: 330 "

3.053 alunos, INGLUINDO OS DEPENDENTES

B - 1. ${ }^{\circ}$ ANO: 293 alunos

2. ANO: 547 "

3. ANO: 395 "

4. ANO: 446 "

5. ANO: 330 "

2.011 alunos EXCLUINDO OS DEPENDENTES

$\mathrm{C}-10^{\circ}$ ANO: 455 alunos

2. ANO: 300 "

3. ANO: $165 "$

4. ANO: 122 "

1.042 alunos, DEPENDENTES 
D - ALUNOS MATRICULADOS: 3.053

ALUNOS DEPENDENTES: 1.042

ALUNOS CURSANDO: $\quad \stackrel{2.011}{ }$

\section{RESUlTADO DO CONCURSO DE HABILITAÇÃo REALIZADO EM 1951}

Candidatos do sexo masculino ................ $\quad 655$

Candidatos do sexo feminino ............... 86

TOTAL $\ldots \ldots \ldots \ldots \ldots \ldots \ldots \ldots \ldots \ldots, 741$

Candidatos que optaram pelo exame de inglês ..... 344

Candidatos que optaram pelo exame de francês... 397

TOTAL $\quad \ldots \ldots \ldots \ldots \ldots \ldots \ldots \ldots \ldots, 741$

Contadores $\quad \ldots \ldots \ldots \ldots \ldots \ldots \ldots \ldots \ldots \ldots \ldots, \quad 82$

Curso Secretariado ...................... 3

Diploma de Ciências Econômicas ............. 1

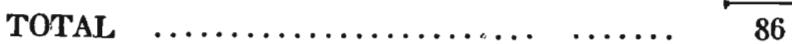

Total de candidatos aprovados no concurso de habilitação: 303

\section{CURSO DE DOUTORADO}

Foi reaberto o Curso de Doutorado, em 1951, ficando as cadeiras distribuidas de acôrdo cam a seguinte seriação:

\section{CATEDRáticos}

\section{1. ${ }^{\circ}$ ANO -}

DIREITO PUBLICO - Teoria Geral do

Estado e Partes Especiais. ...... Prof. Vicente Ráo HISTÓRIA DO DIREITO NACIONAL .. Prof. Waldemar Ferreira DIREITO CIVIL COMPARADO ..... Prof. Lino Leme CRIMINOLOGIA . ........... Prof. Noé Azevedo 


\section{$20^{\circ}$ ANO -}

ECONOMIA E LEGISLAÇÃO SOCIAL

DIREITO FÚBLICO INTERNACIONAL

CIENCIA DÀS FINANÇAS

FILOSOFIA DO DIREITO

Matricularam-se no $10^{\circ}$ ano 316 bachareis e bacharelandos, devendo os mesmos, para aprovação para o $2 .^{\circ}$ ano, apresentar teses e defendê-las; em janeiro de 1952. 


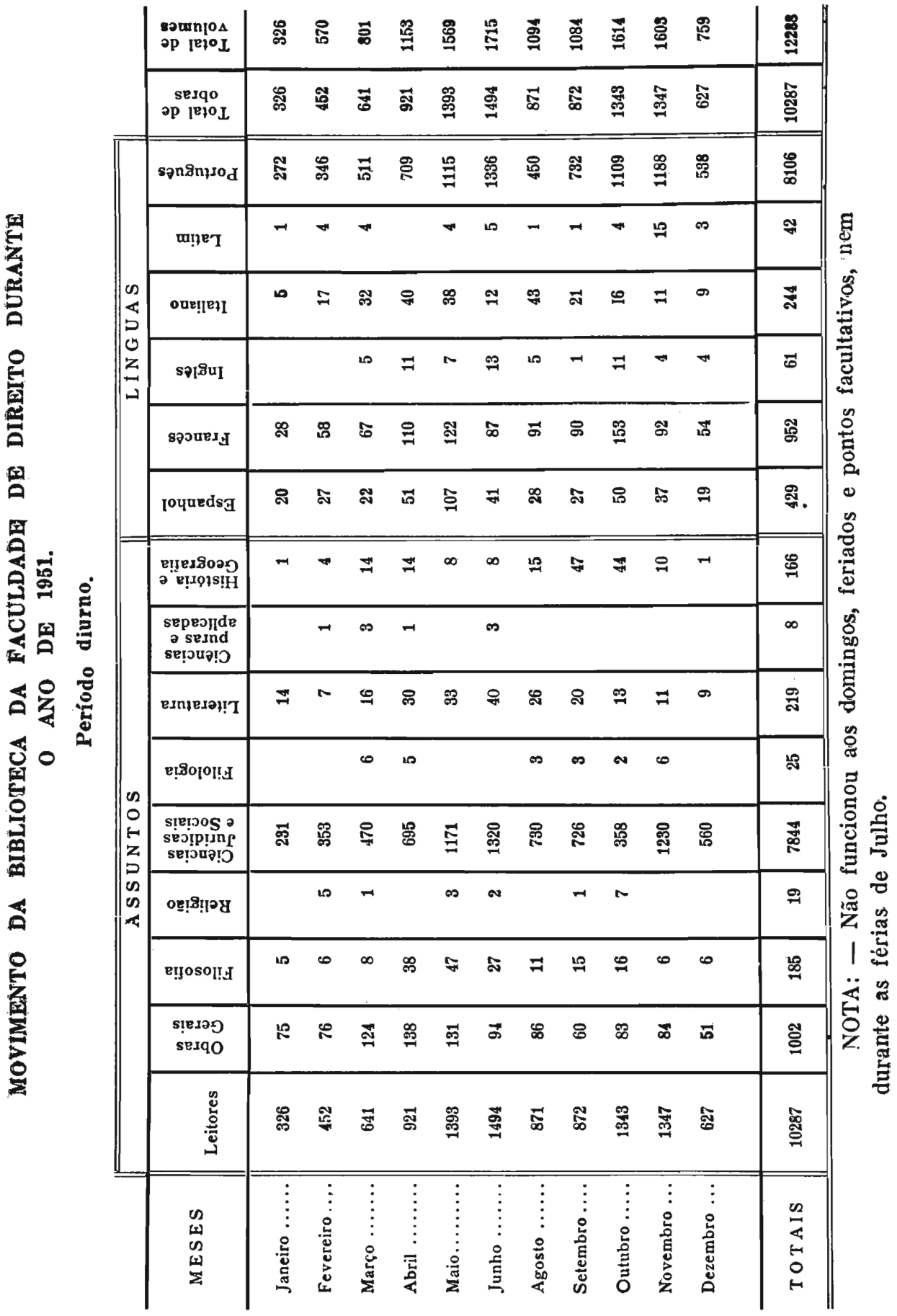




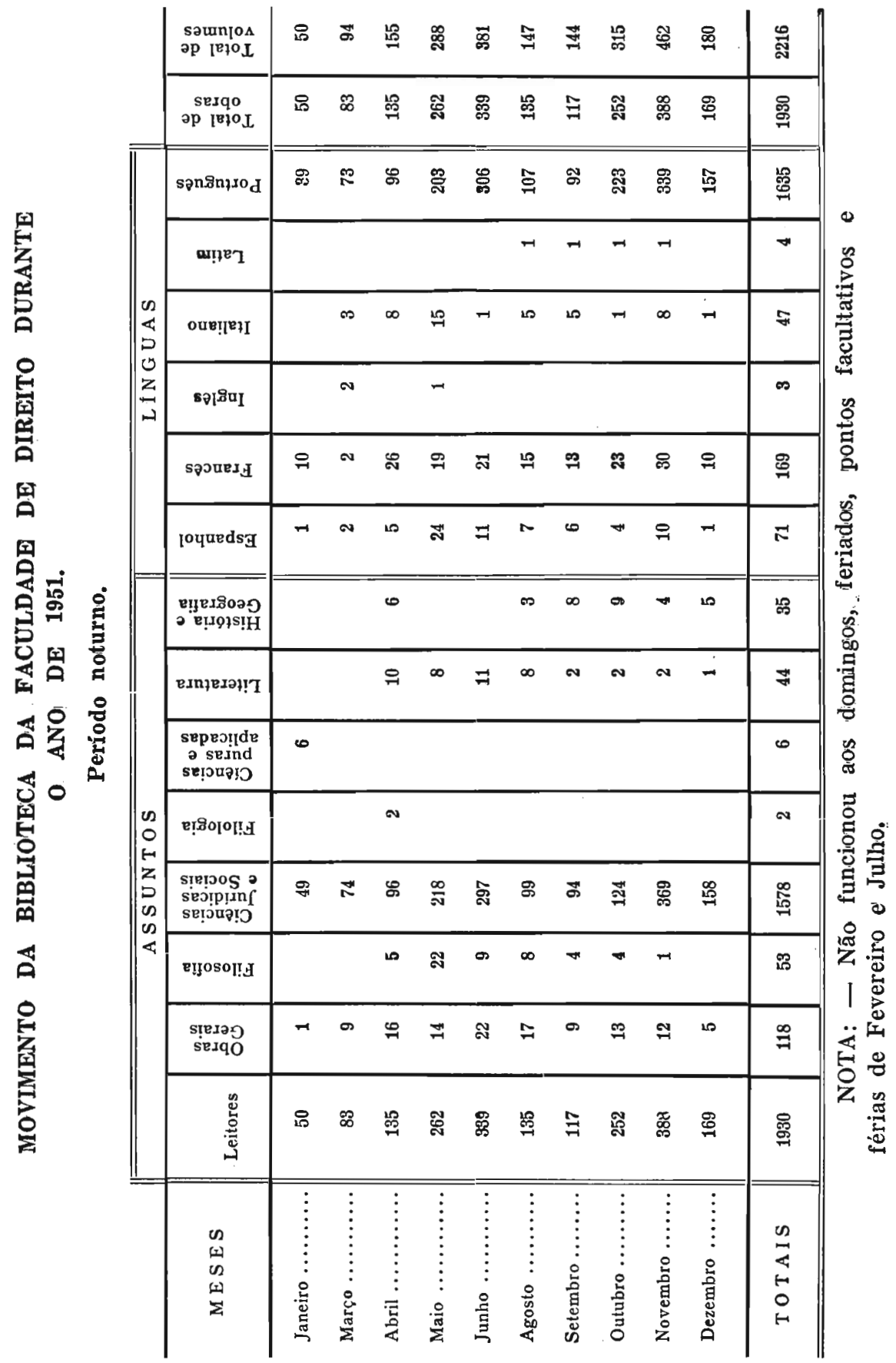




\section{BIBLIOTECA CIRCULANTE}

A Biblioteca Cinculante da Faculdade de Direito iniciou suas atividades de 1951 numa pequena sala em frente ao depósito da grande Biblioteca da Faculdade; em Agosto do mesmo ano, transportou-se para a Sala Avelar Brotero, onde atualmente está instalada.

Acêrvo: foram registrados 3755 livros durante o ano de 1951, subind'o o acêrvo da Biblioteca para 4226 livros registrados. É de notar. entretanto, que nem todos os livros da Biblioteca encontram-se registrados.

Compra de livros: dêsses 3755 livros registrados, foram comprados 350, num valor aproximado de $\mathrm{Cr} \$ 35.000,00$.

Doações: foram doados 3405 livros, que, ou eram duplicatas da outra Biblioteca, ou proveniente's de particulares. Dêstes, os maiores doadores foram: Prof. Braz de Sousa Arruda, Pnof. M. F. Pinto Pereira, Prof. Waldemar Flerreira e Prof. J. J. Cardoso de Melo Neto. Quanto às duplicatas cedidas pela Biblioteca, constavam das coleções Sílvio Portugal, Viuva Gilberto de Arruda Sampaio e Meireles Reis.

A Biblioteca Circulante recebeu ainda, em dinheiro, uma doação feita pelo Prof. Ruy Cirne Lima. do Rio Grande do Sul.

Preparo dos livros: foram preparados e postos em circulação 2400 livros. Do preparo constam: classificação, etiquetagem, etc. Entretanto, todos os livros da Biblioteca, mesmo os que ainda não se acham preparados, já circulam.

Inscrição: inscreveram-se 927 leitones, sendo 502 no $10^{\circ}$ semestre $\theta$ 425 no $2 .^{\circ}$ semestre.

Empréstimos: foi o seguinte o movimento durante o $2 .^{\circ}$ Semestre de 1951:

\begin{tabular}{c|c|c}
\hline & Direito & Gera l \\
\hline Agosto..... & 404 & 608 \\
Setembro .. & 508 & 735 \\
Outubro ... & 466 & 743 \\
Novembro.. & 748 & 857 \\
Dezembro.. & 526 & 660 \\
\hline T O T A L & 2652 & 3603 \\
\hline
\end{tabular}


Em "geral", estão incluidos os empréstimos de Direito, juntamente com Literatura, História, Economia, Religião. Filosofia, etc. E o total de empréstimos da Biblioteca.

No 1. ${ }^{\circ}$ Semestre de 1951, não foram feitas estatísticas do movimento da Biblioteca Circulante porque esta se achava em fase de organização, apesar de já estar funcionando.

\section{Língua :}

\begin{tabular}{c|r|r|r|r|r|c}
\hline & Port. & Fr. & Esp. & It. & Ing. & Outras \\
\hline Dir. & 3022 & 162 & 36 & 28 & 4 & 0 \\
Geral & 3199 & 282 & 48 & 45 & 22 & 6 \\
\hline
\end{tabular}

Encardenação: foram encadernados 560 volumes, sendo 60 nas oficinas da Faculdade, e 500 em encadernador particular.

HORÁRIO: a Biblioteca Circulante funciona todos os dias úteis das 8 às 19 horas, ininterruptamente. Aos sábados o horário é das 9 às 12 horas.

OBRAS REALIZADAS NA FACULDADE FIRMAS OBRAS

Tecnogeral S.A. Comércio e Indústria - Biblioteca Circulante - Isevantamento de um andar na Biblioteca (4. ${ }^{\circ}$ andar)

Galeria Paulista de Modas Ltda. - Instalação da Sala "Filosofia do Direito"

J.P. Machado - Instalação completa de un "toilette" no andar térreo. 